\title{
Colonização do xilema de eucalipto por Ceratocystis spp. isolado de diferentes hospedeiros
}

\author{
Ana Carolina Firmino'; Francisco André Ossamu Tanaka²; Stela Dalva Vieira Midlej Silva ${ }^{3}$; Margarida Fumiko Ito ${ }^{4}$, \\ Edson Luiz Furtado5.
}

${ }^{1}$ UNESP/Campus Experimental de Dracena, Rodovia Comandante João Ribeiro de Barros, Km 651 - Das Antas, cep: 17900-000, Dracena, SP; ${ }^{2}$ USP/ESALQ - Depto. de Fitopatologia e Nematologia - C.P. 09 - 13418-900 - Piracicaba, SP - Brasil; ${ }^{3}$ CEPLAC - Seção de Fitopatologia - CP. 07 - 45600-970 - Itabuna, BA, Brasil; ${ }^{4}$ APTA/IAC - C.P. 28 - 13001-970 - Campinas, SP - Brasil; ${ }^{5}$ FCA/UNESP - Depto. Produção Vegetal/Defesa Fitossanitária - CEP - 18610-307- Botucatu, SP - Brasil.

Autor para correspondência: Ana Carolina Firmino (anacarfir@gmail.com)

Data de chegada: 18/11/2014. Aceito para publicação em: 30/03/2015.

$10.1590 / 0100-5405 / 2061$

\section{RESUMO}

Firmino, A.C.; Tanaka, F.A.O.; Silva, S.D.V.M.; Ito, M.F.; Furtado, E.L. Colonização do xilema de eucalipto por Ceratocystis spp. isolado de diferentes hospedeiros. Summa Phytopathologica, v.41, n.2, p.138-143, 2015.

Ceratocystis sp. é um fungo que coloniza o xilema, agente causal de murcha e seca em diversas plantas lenhosas. O presente trabalho teve como objetivo acompanhar a colonização deste fungo na superfície de plantas de eucalipto (Eucalyptus sp.). Foram utilizados 5 isolados de Ceratocystis de diferentes hospedeiros (eucalipto, cacau, manga, teca e atemóia). Para isso, plantas de eucaliptos (clone 219) tiveram parte do seu sistema vascular exposto. Nesta região foi depositada uma suspensão contendo $10^{6}$ esporos. Como testemunha, uma planta foi inoculada somente com água destilada autoclavada. Após a inoculação, estas plantas foram mantidas em câmara úmida a $25^{\circ} \mathrm{C}$ no escuro. Parte da área inoculada foi coletada em intervalos de tempo pré-determinados (6, 12 e 24 horas), e fixadas em solução de "Karnovsky". As amostras foram preparadas e analisadas ao microscópio eletrônico de varredura.
Todos os isolados foram capazes de germinar, penetrar e se desenvolver nos elementos de vasos de plantas de eucalipto no período de 6 horas. O isolado de cacau foi o que aparentemente teve o desenvolvimento mais lento dentro dos períodos estudados. Foi observada a germinação de ascósporos, clamidósporos e de conídios do tipo cilíndrico neste período. Doze horas após a inoculação ocorreu aumento da quantidade de micélio de todos os isolados testados. Nos casos dos isolados de manga e eucalipto foi possível observar a formação de novos clamidósporos. Vinte e quatro horas após a inoculação, com exceção do isolado de cacau, todos os outros isolados já apresentavam a formação de conidióforos cilíndricos. Este estudo comprova que isolados deste fungo, mesmo que provindos de outros hospedeiros, são capazes de se desenvolver no xilema do eucalipto.

Palavras-chave adicionais: patogenicidade, desenvolvimento, vasos

\section{ABSTRACT}

Firmino, A.C.; Tanaka, F.A.O.; Silva, S.D.V.M.; Ito, M.F.; Furtado, E.L.. Colonization of eucalyptus xylem by Ceratocystis spp. isolated from different hosts. Summa Phytopathologica, v.41, n.2, p.138-143, 2015.

Ceratocystis sp. is a fungus that colonizes the xylem and acts as the causal agent of wilt and drought in several woody plants. The present study aimed to monitor the colonization of this fungus on the surface of eucalyptus plants (Eucalyptus sp.). Five Ceratocystis isolates from different hosts (eucalyptus, cocoa, mango, teak and atemoya) were used. Thus, eucalyptus plants (clone 219) had part of their vascular system exposed. A suspension containing $10^{6}$ spores was deposited onto this region. As a control treatment, one plant was inoculated only with autoclaved distilled water. After inoculation, those plants were kept in a humid chamber at $25^{\circ} \mathrm{C}$ in the dark. Part of the inoculated area was collected at predetermined time intervals (6,12 and 24 hours) and fixed in "Karnowsky" solution. The samples were prepared and analyzed under a scanning electron microscope. All isolates were capable of germinating, penetrating and developing in the vessel elements of eucalyptus plants within 6 hours. The cocoa isolate apparently had the slowest development within the studied periods. Germination of ascospores, chlamydospores and conidia of cylindrical type could be observed in this period. Twelve hours after inoculation, the amount of mycelium increased in all tested isolates. In cases of mango and eucalyptus isolates, formation of new chlamydospores could be observed. Twenty-four hours after inoculation, except for cocoa isolates, all other isolates already exhibited formation of cylindrical conidiophores. This study demonstrates that these fungal isolates, even from other hosts, are capable of developing in the xylem of eucalyptus plants.

Additional keywords: pathogenicity, development, vessel

No Brasil são reconhecidas somente as presenças de três espécies: C. paradoxa, atacando principalmente monocotiledôneas, $C$. cacaofunesta acarretando grandes problemas em plantações de cacau
(3), e C. fimbriata, causadora de doença em muitas plantas lenhosas, como em eucalipto (8). Novos estudos realizados por Van Wyk et al. (21), com vários isolados de manga de diferentes regiões, sugerem que 
os isolados do Brasil não tenham relação com os isolados de outros países e que ainda os isolados brasileiros sejam divididos em dois grupos distintos, sendo que um grupo seja classificado como C. mangicola e outro como C. mangivora. Plantas infectadas por Ceratocystis têm como sintoma característico o escurecimento do feixe do xilema, em geral da periferia para a medula. Este escurecimento é decorrente do colapso dos vasos do xilema causado pela invasão do fungo.

Segundo Harrington et al. (15), o gênero Ceratocystis pode ser dividido em quatro grupos ou clados distintos: o da América Latina, o da América do Norte, o da Ásia e o da África. Dentro do clado da América Latina, Baker et al. (2) estudaram diferentes isolados de cacau, Herrania sp., batata-doce, Platanus sp., café, manga, Annona sp., eucalipto e Gmelina sp. e verificaram, com base nos teste de patogenicidade que há uma especialização em nível de hospedeiro dentro desse clado. Dessa maneira, Baker et al. (2) levantaram a hipótese de que populações locais de C. fimbriata são hospedeiro-especializados. Com base nesses estudos foi sugerido que a evolução e a divergência das espécies de Ceratocystis podem ter sido conduzidas pela especialização por hospedeiro, , já que existe pequenas diferenças morfológicas entre as espécies destes fungos (9).

Apesar destes fatos, estudando isolados do clado na América do Norte, Johnson et al. (16) observaram, em testes de patogenicidade cruzada, que alguns isolados foram capazes de causar doença em plantas que não eram da espécie do seu hospedeiro original. Os autores notaram que mudas de cereja (Prunus sp.) quando eram inoculadas com isolados de Ceratocystis provindos de Quercus sp., apresentavam descololaração do xilema similar quando eram inoculadas com isolados de Ceratocystis de cereja. O mesmo aconteceu com plantas de Carya sp. e Populus sp. quando inoculadas com isolados de cereja.

Há relatos de isolados de C. fimbriata de Syngonium da Austrália que não conseguiram infectar Ipomoea batatas, Platanus orientalis ou Prunus spp., mas foram patogênicos para várias cultivares de Syngonium sp., Caladium sp., Alocasia sp. e X. lindenii (22), e isolados japoneses de Colocasia foram patogênicos a Ipomoea batatas, e de isolados japoneses de Ipomoea batatas serem patogênicos a plantas Ipomoea batatas, mas não para Colocasia esculenta (2)

Alguns trabalhos apontam que isolados brasileiros de Ceratocystis têm mostrado variação na agressividade e baixa especialização no hospedeiro $(2,19,23)$. Firmino (10) observou em seu trabalho que plantas de eucalipto, inoculadas com isolados deste fungo procedentes de cacau, manga, atemóia e teca, demonstraram escurecimento de seu xilema, mesmo que pequeno, quando comparados com o tamanho das lesões causadas pelos isolados de eucalipto. Esta informação, juntamente com o fato de que a maioria destes isolados foi capaz de crescer em isca de cenoura quando reisolados de plantas de eucalipto aponta que este fungo é capaz de se adaptar e invadir os vasos de plantas que não estejam relacionados com aquela de que ele foi isolado originalmente .

Estudos de microscopia da interação patógeno-hospedeiro são um recurso eficaz para compreender a patogênese, e, finalmente, levar a elucidação dos mecanismos de resistência do hospedeiro (1). Diante deste problema e da importância que este patógeno vem tomando dentro da cultura do eucalipto, o presente trabalho teve como objetivo acompanhar a colonização dos vasos do xilema de eucalipto por Ceratocystis, quando estes são inoculados com isolados deste fungo provindo de diferentes espécies hospedeiras.

\section{MATERIAL E MÉTODOS}

Os isolados foram obtidos da Micoteca do Laboratório de Patologia Florestal do Departamento de Produção Vegetal, Defesa Fitossanitária da Faculdade de Ciências Agronômicas da UNESP, Botucatu-SP. Estes já foram identificados morfologicamente e por ferramentas moleculares (10). Foram usados cinco isolados de Ceratocystis, de diferentes hospedeiros: isolado AFC 01 de manga (C. mangicola) (20), isolado ACF 15 de cacaueiro (C. cacaofunesta) (11), isolado ACF 25 de atemóia (C. fimbriata) (12), isolado ACF 38 de eucalipto (C. fimbriata) (14) e isolado ACF 50 de teca (C. fimbriata) (13).

Para o acompanhamento da colonização do xilema de eucalipto por alguns isolados de Ceratocystis sp., foram utilizadas 5 mudas do clone 219 (E. urophylla $\mathrm{x}$ E. grandis ), com seis meses de idade. Estas plantas tiveram parte do seu sistema vascular exposto com o auxílio de uma lâmina de bisturi estéril. Sobre esta área foi depositada $40 \mathrm{uL}$ de uma suspensão contendo $10^{6}$ esporos cilíndricos $/ \mathrm{mL}$ de cada isolado. Como testemunha uma planta foi inoculada somente com água esterilizada.

Após a inoculação, estas plantas foram mantidas em câmara úmida a $25{ }^{\circ} \mathrm{C}$ no escuro. Parte da área inoculada (cerca de $5 \mathrm{~mm}$ de comprimento) foi coletada em intervalos de tempo pré-determinados $(6,12$ e 24 horas) e fixadas em solução de "Karnovsky" (glutaraldeido 2,5\%, paraformaldeído 2,0\%, tampão fosfato $0,05 \mathrm{M}, \mathrm{pH} 7,2$ ), por um período mínimo de 24 horas, para serem preparadas e analisadas ao microscópio eletrônico de varredura LEO435-VP. Foram usadas três plantas para cada intervalo de tempo pré-determinados.

As amostras do caule inoculadas foram retiradas do fixador "Karnovsky" e transferidas para microtubos de 1,5 mL contendo tampão fosfato de sódio $0,05 \mathrm{M}$, onde permaneceram por dez minutos. O tampão foi trocado três vezes. Subsequentemente as amostras foram desidratadas em séries crescentes de concentração de acetona (30\%, $50 \%, 70 \%, 90 \%$ - 10 minutos cada e $100 \%$ por três vezes de 10 minutos). Após esta etapa, as amostras foram levadas ao aparelho de ponto crítico (Baltec CPD 030) para completar a secagem. Após completa desidratação das amostras, estas foram cuidadosamente montadas em "stubs" com fita de carbono dupla face para aderência das amostras e cobertas com $20 \mathrm{~nm}$ de ouro em aparelho Baltec SCD 050. A preparação e observação das amostras foram feitas no Centro de Microscopia Eletrônica, ESALQ/USP, Piracicaba-SP.

\section{RESULTADOS E DISCUSSÃO}

Como pode ser observado nas Figuras 1, 2 e 3, os isolados estudados foram capazes de germinar, penetrar e se desenvolver nos vasos de plantas de eucalipto. O isolado de cacau foi o que aparentemente teve o desenvolvimento mais lento dentro dos períodos observados (Figura 1). Isto pode ser explicado pelo fato deste isolado ser uma espécie de Ceratocystis diferente do que é encontrada em eucalipto. A espécie encontrada em cacaueiro foi recentemente renomeada como C. cacaofunesta (7). Estes autores ao realizarem estudos sobre características morfológicas das linhagens hospedeiro-especializadas, e com base nos resultados obtidos por esses autores, os isolados, que antes era designada $C$. fimbriata, que atacavam cacau e Platanus sp, foram renomeados como C. cacaofunesta e C. platani, respectivamente (9).

No período de seis horas após a inoculação, foi observado que os isolados testados já haviam emitido o tubo germinativo e penetrado na planta (Figuras 1, 2 e 3). Foi observado, neste periodo a germinação de ascósporos, clamidósporos e de conídios do tipo cilíndrico neste período. É interessante ressaltar que este fungo parece usar os poros do 

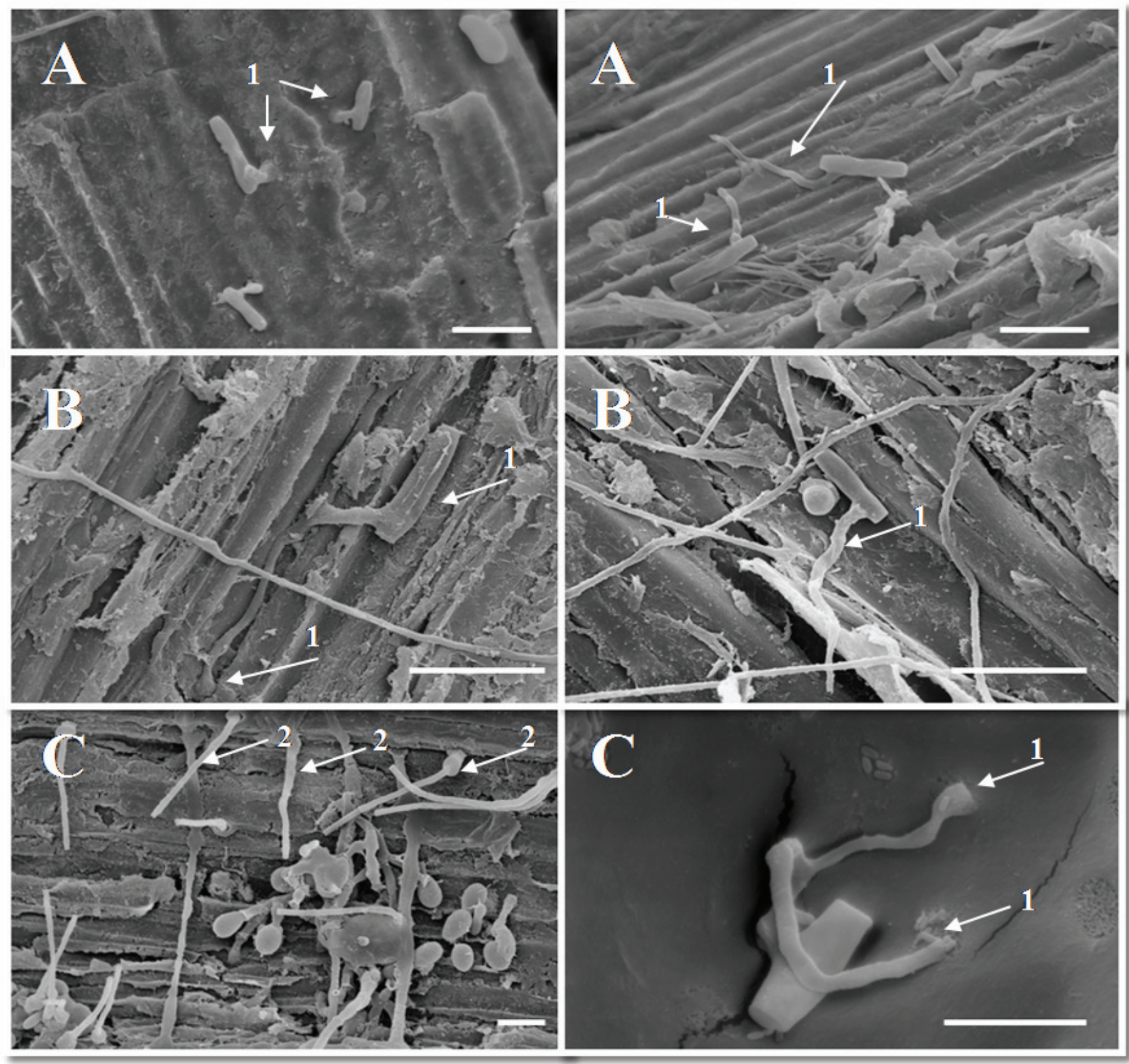

Figura 1. Colonização do xilema de eucalipto por Ceratocystis spp. (Isolado ACF 01 de mangueira na esquerda e ACF 15 de cacaueiro à direita). A. 6 horas após a inoculação. B: 12 horas após a inoculação. C: 24 horas após a inoculação. 1: Esporos germinando e penetrando; 2: conidióforo; Barras: A, B e C: $20 \mu \mathrm{m}$;

xilema para invasão das células (Figura 2). Esta observação em relação à invasão do fungo também foi feita por D'Ambra et al. (5). Estes autores ao estudarem o desenvolvimento de C. platani sobre os tecidos de plátano (Platanus orientalis), um ano após a inoculação, notaram que fungo após penetrar pelas lesões, evolui rapidamente ao longo dos raios medulares para a medula e finalmente, nos elementos do xilema. Estes autores ainda citam que a presença de hifas em células da medula provoca a degradação da lamela média da planta e as paredes internas dos vasos não foram afetadas pela atividade das hifas.

Doze horas após a inoculação, nota-se o aumento da quantidade de micélio na região do xilema de todos os isolados testados (Figuras
1,2 e 3). No caso dos isolados de manga e eucalipto, neste período já foi possível observar a formação de novos clamidósporos. Sobre a superfície inoculada com o isolado de eucalipto, particularmente, pode-se ver a formação de conidióforos. Para alguns fungos a produção de conídios durante as primeiras fases de colonização pode ser a chave para a rápida distribuição do fungo (6). Além disso, também foi observado somente na superfície inoculada com o isolado de eucalipto, a presença de cristais de oxalato de cálcio (Figura 3), que não foram visualizados nos períodos anteriores em nenhum dos casos análisados. Estes cristais podem estar relacionados com a interação deste fungo com seu hospedeiro especifico, assim este fato deve ser melhor estudado.

No período de vinte e quatro horas após a inoculação não foi 

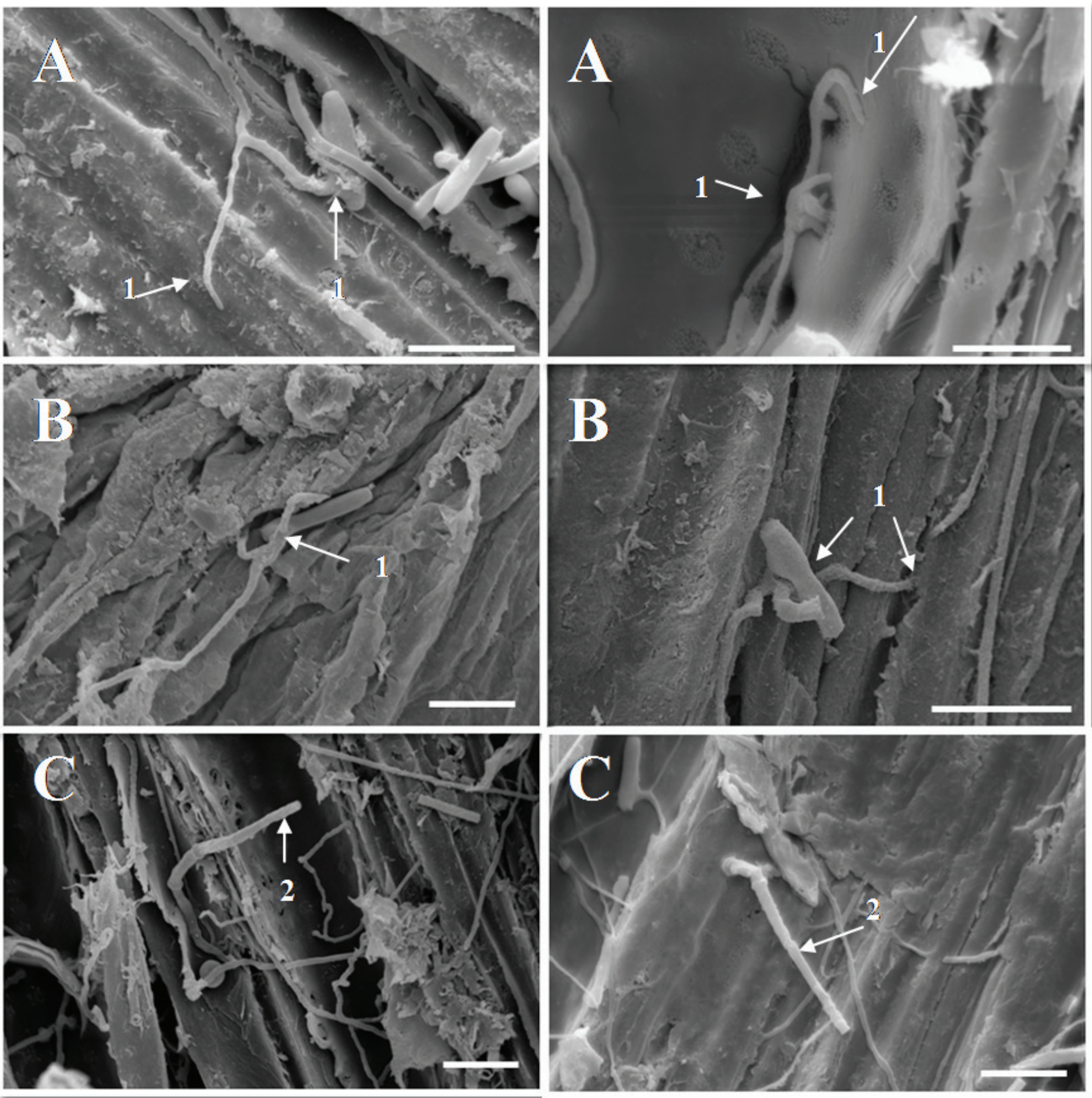

Figura 2. Colonização do xilema de eucalipto por Ceratocystis spp. (isolado ACF 25 de atemoia a esquerda e isolado ACF 50 de teca a direita). A. 6 horas após a inoculação. B: 12 horas após a inoculação. C: 24 horas após a inoculação. 1: Esporos germinando e penetrando; 2: conidióforo; Barras: A, B e C: $20 \mu \mathrm{m}$;

observada a formação de peritécios. Santos et al. (18), em estudos de acompanhamento da colonização de C. cacaofunesta sobre tecidos de plantas cacaueiro, somente observaram a formação de peritécios do fungo dois dias após a inoculação, sendo que estes apenas ficaram maduros cerca de quatro dias após a inoculação.

Neste mesmo período, porém todos os outros isolados testados, com exceção do isolado de cacau, já apresentaram a formação de conidióforos cilíndricos (Figuras 1, 2 e 3). Em todos estes conidióforos é possível observar a saída dos esporos, indicando que neste período este fungo já está apto a produzir novos conídios. O mesmo pode ser observado no trabalho de Santos et al. (18).

O crescimento das hifas do patógeno e produção de esporos, num curto espaço de tempo no interior do vaso, eventualmente, podem obstruir as perfurações nos elementos da traqueia, provocando estresse e falta de água na parte superior das plantas. Este estresse também pode ser atribuído ao aumento da viscosidade da seiva, resultante da ação enzimática no tecido do xilema, como no caso dos glicopéptidos produzidos por C. ulmi (17). 

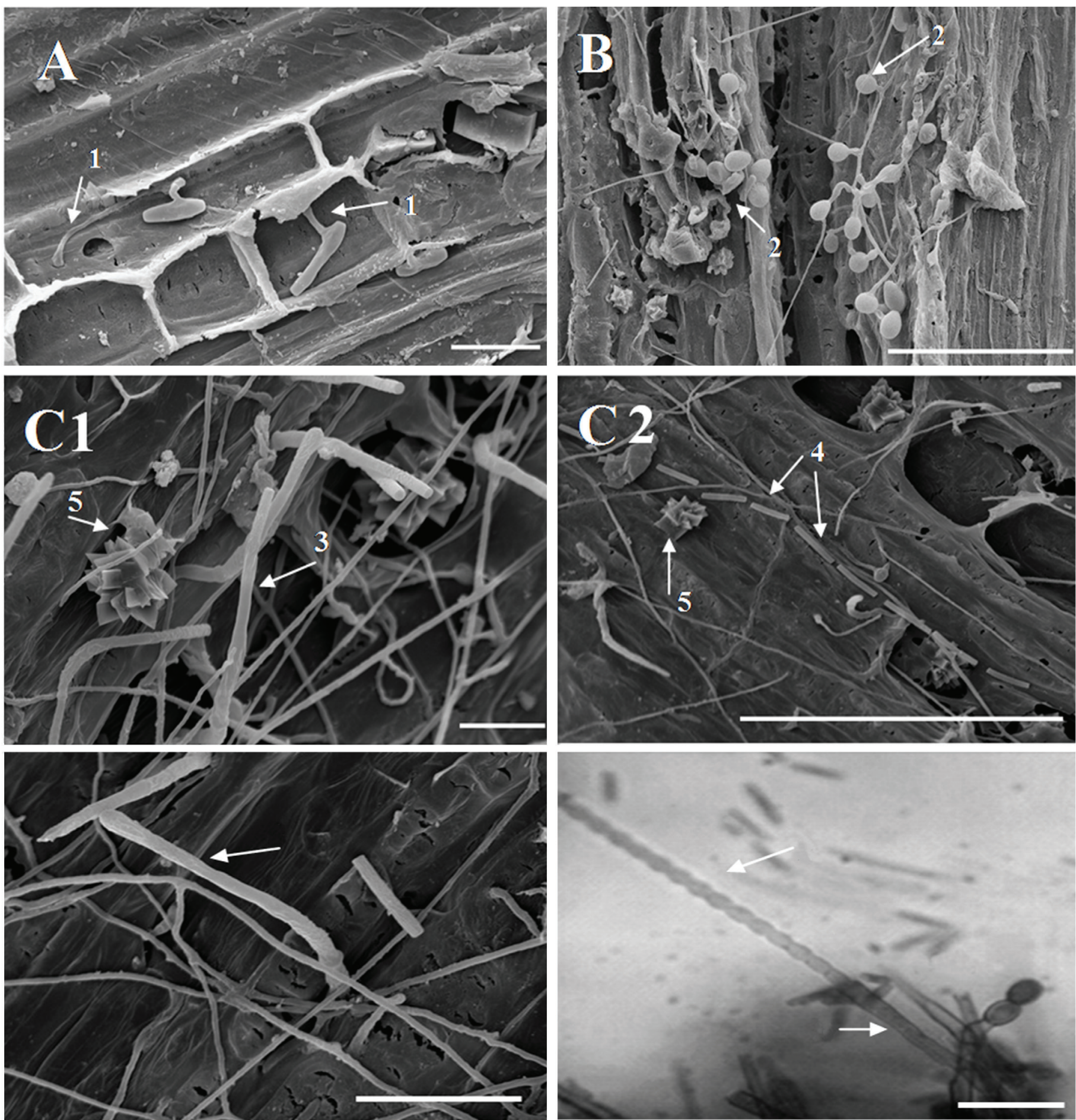

Figura 3. Colonização do xilema de eucalipto por Ceratocystis spp. (isolado ACF 38 de de eucalipto). A. 6 horas após a inoculação. B: 12 horas após a inoculação. C: 24 horas após a inoculação. 1: Esporos germinando e penetrando; 2: conidióforo; 3: Endoconidióforos cilíndricos; 4: Novos conídios cilíndricos; 5: Cristais de oxalato de cálcio; Endoconidióforos (E) e endoconídios doliformes (e); Barras: A e C1: 20 um; B e C2: 100 $\mu \mathrm{m}$; $\mathrm{C} 3$ e $\mathrm{C} 4: 30 \mu \mathrm{m}$.

Após a formação do conidióforo na maioria dos isolados, notou-se a diferença morfológica na base do conidióforo do isolado ACF 15 de manga. Na inserção desta estrutura fúngica no tecido vegetal ocorreu uma dilatação na base, conferindo a este um formato diferente dos conidióforos dos outros isolados testados. Esta diferenciação micro- morfológica pode colaborar com a hipótese levantada por VAN WyK et al. (20). Estes autores estudando a taxonomia, morfologia, além de aspectos moleculares, de vários isolados de manga de diferentes regiões, incluindo o isolado ACF1 (CMW27306) sugeriram que os isolados do Brasil deixem de serem tratados como pertencentes somente a espécie 
de C. fimbriata (20). Por exemplo, estes autores citam que isolados de $C$. mangicola têm ostíolos divergentes e convergentes e esta é uma característica que não tem sido descritos para outras espécies de $C$. fimbriata.

Nas amostras inoculadas com os isolados de eucalipto (ACF38), foi possível observar a presença de um segundo tipo de conidióforo, que produz conídios do tipo doliforme (Figura 3). A presença desses esporos pode indicar a presença de uma nova espécie de Ceratocystis no Brasil, visto que na literatura não há indicações que $C$. fimbriata produzindo este tipo de esporo, e esta é única espécie deste fungo relatada infectando eucalipto no Brasil.

A probabilidade de novas espécies, que não C. fimbriata, atacando plantas de eucalipto na América Latina foi comprovada por Bodas et al. (4). Estes autores através de análises morfológicas e moleculares relataram a existência de $C$. neglecta infectando plantas de $E$. grandis. Van Wyk et al. (21), relatam a ocorrência de C. moniliformis em eucalipto no Equador. Estes mesmos autores ainda citam a provável existência de mais duas novas espécies de Ceratocystis atacando plantas de eucalipto neste país, C. curvata sp. nov., C. ecuadoriana sp. nov. e $C$. diversiconidia sp. nov. Todas estas novas espécies relatadas por estes autores têm como característica a presença de conídios do tipo doliformes.

\section{AGRADECIMENTOS}

À FAPESP (Processo 2011/05710-0) e a CNPq pelo auxílio financeiro, ao Núcleo de Apoio à Pesquisa em Microscopia Eletrônica da ESALQ/USP, CEPLAC and APTA/IAC/Campinas.

\section{REFERÊNCIAS}

1. Araujo, J.C.A; Matsuoka, K. Histopatologia da interação Alternaria solani em tomateiros resistentes e suscetíveis. Fitopatologia Brasileira, Brasília, DF, v. 29, p. 268-275, 2004.

2. Baker, C.J.; Harrington, T.C.; Krauss, U.; Alfenas, A.C. Genetic variability and host specialization in the Latin American clade of Ceratocystis fimbriata. Phytopathology, St. Paul, v. 93, p. 1274-1284, 2003.

3. Bezerra, J. L. Ceratocystis fimbriata causing death of budded cocoa seedlings in Bahia, Brazil. Incoped Newsletter, Malasia, v. 1, p. 6, 1997.

4. Bodas, C.A.; Roux. J.; Van WyK, M.; Wingfield, B.D.; Wingfield, M.J.; Ceratocystis neglecta sp. nov. infecting Eucalyptus trees in Colombia. Fungal Diversity, Dordrecht, v.28, p. 73-84, 2008.

5. D'Ambra, V.; Ferrata, M.; Baldan, B.P. Growth and behaviour of Ceratocystis fimbriata in plane-tree tissues a scanning electron microscope study. European Journal of Forest Pathology, Hamburg, v.7, p. 351-357, 1977.

6. Duncan, D.R.; Himelick, E.B. Conidial production of Verticillium dahliae as influenced by a negative pressure potential. Canadian Journal Botany, Ottawa, v.66, p. 67-71, 1988.

7. Engelbrecht, C.J.B.; Harrington, T.C. Intersterility morphology and taxt onomy of Ceratocystis fimbriata on sweet potato cacao and sycamore. Mycologia, New York, v. 97, p.57-69, 2005.
8. Ferreira, F. A.; Demuner, A. M.; Demuner, M. L; Pigato, S. Murcha de Ceratocystis em eucalipto no Brasil. Fitopatologia Brasileira, Brasília, DF, v. 24, p. 284, 1999.

9. Ferreira, M. A. Estrutura genética de populações de Ceratocystis fimbriata e padrão espaço-temporal da murcha-de-Ceratocystis. 2009. 107 f. Tese (Doutorado em Fitopatologia)-Universidade Federal de Viçosa, Viçosa, MG, 2009.

10. Firmino, A. C. Caracterização de isolados de Ceratocystis sp., avaliação de resistência clonal de eucalipto e sensibilidade deste fungo a diferentes fungicidas. 2011. 105 p. Tese (Doutorado em Agronomia/Proteção de Plantas) - Faculdade de Ciências Agronômicas, Universidade Estadual Paulista. Botucatu. 2011.

11. Firmino, A.C.; Silva, S.D.V.M.; Furtado, E.L. Characterization of isolates of Ceratocystis sp. collected from cocoa plants. In: $17^{\text {th }}$ International Cocoa Research Conference, Resumos...Cameron-Africa. COPAL/CATIE, 2012. (CD-rom)

12. Firmino, A.C.; Tozze Júnior, H.J.; Costa, P.N.; Furtado, E.L. Ceratocystis fimbriata causando seca em atemóia na região de Botucatu-SP . Summa phytopathologyca, Botucatu, v. 38, p. 171-171, 2012.

13. Firmino, A.C.; Tozze Júnior, H.J.; Furtado, E.L. First report of Ceratocystis fimbriata causing wilt in Tectona grandis in Brazil. New Disease Reports, Reading, v.25, p. 24, 2012.

14. Firmino, A.C.; Tozze Júnior, H.J.; Gava de Souza, I.C.; FURTADO, E.L. Resistência de genótipos de eucalipto a Ceratocystis spp. Scientia Forestalis, Piracicaba, v. 41, p.165-173, 2013.

15. Harrington, T.C.; Thorpe, D.J.; Alfenas, A.C. Genetic variation and variation in aggressiveness to native and exotic hosts among Brazilian populations of Ceratocystis fimbriata. Phytopathology, St. Paul, v.101, p. 555-566, 2011.

16. Johnson, J.A.; Harrington, T.C.; Engelbrewcht, C.J.B. Phylogeny and taxonomy of the North American clade of the Ceratocystis fimbriata complex. Mycologia, v. 97, p.1067-1092, 2005.

17. Pascholati, S.F.; Leite, B.; Stangarlin, J.R.; CIA, P. Interação planta-patógeno: Fisiologia Bioquímica e Biologia Molecular. 1th Ed. Piracicaba SP. Fealq, 2008. 627 p.

18. Santos, R.M.F.; Silva, S.D.V.M.; Sena, K.; Micheli, F.; Gramacho, K.P. Kinetics and histopathology of the Cacao-Ceratocystis cacaofunesta interaction. Tropical Plant Biology, New York, v.6, p. 37-45, 2013.

19. Thorpe, D.J.; Harrington, T.C.; Uchida, J.Y. Pathogenicity internal trant scribed spacer-rDNA variation and human dispersal of Ceratocystis fimbriata on the family Araceae. Phytopathology, v.95,p. 316-323, 2005.

20. Van WyK, M.; Wingfield, B.D.; Al-Adawi, A.O.; Rosetto, C.; Ito, M.F.; Wingfield, M.J.; (2010) Two new Ceratocystis species associated with mango disease in Brazil. Available at: http://repository.up.ac.za/bitstream/hand1e/2263/19482/VanWyk_Two\%282011\%29.pdf?sequence=1\&isAllowed=y. Accessed on October 8, 2011.

21. Van WyK, M.; Wingfield, B.D.; Wingfield, M.J. Four new Ceratocystis spp. associated with wounds on Eucalyptus, Schizolobium and Terminalia trees in Ecuador. Fungal Diversity, Dordrecht, v.46, p.111-131, 2011.

22. Vogelzang, B.K.; Scott, E.S. Ceratocystis fimbriata causal agent of basal rot of Syngonium cultivars and host range studies of isolates of $C$. fimbriata in Australia. Plant Pathology, Oxford, v.19, p.82-89, 1990.

23. Zauza, E.A.V.; Alfenas, A.C.; Harrington, T.C.; Mizubuti, E.S.; Silva, J.F. Resistance of Eucalypt clones to Ceratocystis fimbriata. Plant Disease, St. Paul, v.88, p.758-760, 2004. 